\title{
PEMODELAN PERMUKAAN DIGITAL DATA MAGNETIK SURVEI GEOFISIKA UDARA MENGGUNAKAN METODE GEOSTATISTIKA UNTUK EKSPLORASI MINERAL (Daerah Studi: Wilayah Komopa, Papua)
}

\author{
HARY NUGROHO ${ }^{1,2}$, DEWI KANIA SARI ${ }^{1}$, RIKA HERNAWATI ${ }^{1}$ \\ ${ }^{1}$ Jurusan Teknik Geodesi - FTSP, Institut Teknologi Nasional (Itenas) Bandung \\ ${ }^{2}$ Program Studi Geodesi \& Geomatika - FITB, Institut Teknologi Bandung (ITB) \\ Email: hary@itenas.ac.id
}

\begin{abstract}
ABSTRAK
Dalam interpretasi data, data hasil survei geofisika udara umumnya perlu diubah menjadi model permukaan digital atau digital terrain model (DTM). Hal ini sebagai langkah untuk memudahkan dalam memahami kondisi data secara keseluruhan. Untuk membuat DTM banyak metode yang dapat diterapkan. Salah satu di antaranya adalah dengan metode Geostatistika Kriging. Penerapan metode Geostatistika Kriging dapat menggunakan berbagai macam teknik di antaranya adalah teknik Simple Kriging dan Disjunctive Kriging. Dalam penelitian ini dilakukan pengolahan DTM untuk data magnetik dengan menggunakan kedua teknik ini dengan aproksimasi Gaussian Kernel dan Density Skew. Wilayah studi pada penelitian ini adalah wilayah Komopa, Kabupaten Painai, Provinsi Papua yang merupakan wilayah Kontrak Karya PT. Freeport Indonesia. Adapun data yang digunakan adalah data hasil survei geofisika udara yang dilakukan pada periode 1983-1984. Hasil pemodelan yang diperoleh dari kedua teknik tersebut selanjutnya dibandingkan dan diperoleh hasil bahwa teknik Disjunctive Kriging dengan aproksimasi Density Skew lebih baik daripada teknik Simple Kriging dengan aproksimasi Gaussian Kernels maupun Density Skew.
\end{abstract}

Kata kunci: survei geofisika udara, magnetik, DTM, geostatistika, kriging

\begin{abstract}
In data interpretation, airborne geophysical survey results generally need to be transformed into a digital terrain model (DTM). This is an effort to facilitate in understanding the condition of the whole of data. To make the DTM, many methods can be applied. One of them is Kriging geostatistical method. Application of Kriging geostatistical method can use various techniques such as Simple Kriging and Disjunctive Kriging technique. In this research DTM processing for magnetic data has been performed by using both of these techniques with Gaussian Kernel and Density Skew approximation. The study area in this study is the area of Komopa, Painai District, Papua Province which is the area of Work Contract of PT. Freeport Indonesia. The data used is the data of airborne geophysical survey conducted in the period 1983-1984. The modelling results from the two techniques were then compared and the results showed that the Disjunctive Kriging technique with Density Skew approximation is better than Simple Kriging technique with Gaussian Kernels and Density Skew approximation.
\end{abstract}

Keywords: airborne geophysical survey, magnetic, DTM, geostatistics, kriging

Reka Geomatika - 82 


\section{PENDAHULUAN}

Dalam eksplorasi sumberdaya mineral pada wilayah yang luas, teknologi yang digunakan umumnya adalah teknologi survei geofisika udara. Teknologi ini adalah teknik survei geofisika yang menggunakan wahana pesawat udara (airborne geophysic survey) yang meliputi survei gaya berat (gravity), elektromagnetik, magnetik, radiometrik, dan gravity gradiometric. Pada tahun 1957 teknologi ini telah diterapkan di Inggris untuk melakukan eksplorasi mineral (Cornwell dkk., 1995). Hasil dari survei ini digunakan untuk mengidentifikasi target yang dicari atau mencari korelasi dari variasi spasial dari besaran parameter yang diukur terhadap variasi dari geologi (Scott, 2014).

Data yang diperoleh dari survei geofisika udara ini umumnya harus diintegrasikan agar dapat menunjukkan lokasi mineral yang diinginkan. Untuk itu diperlukan suatu sistem yang dapat mengintegrasikan data dari berbagai sumber ini untuk dapat menggambarkan secara utuh kondisi lapisan batuan pada lokasi survei. Sistem tersebut berupa Sistem Informasi Geografis (SIG). Saat ini SIG telah banyak digunakan oleh para pakar ilmu kebumian (geoscientis) untuk mengintegrasikan data geologi, geokimia, dan geofisika untuk melakukan kompilasi dan interpretasi sinergis dalam eksplorasi mineral dalam skala proyek eksplorasi regional, lokal, dan rinci (IAEA, 2013). Dengan sistem ini data hasil survei geofisika dapat divisualisasikan secara terintegrasi (Yanbing dkk., 2007).

Untuk visualisasi data dalam SIG, data hasil survei geofisika udara harus dibuat dalam model permukaan digital (Digital Terrain Model-DTM) sehingga lokasi wilayah dugaan deposit mineral dapat dideteksi. Pemodelan dapat dilakukan dengan menggunakan metode interpolasi spasial seperti geostatistika atau teknik interpolasi lainnya (Guastaldi dkk., 2013). Dalam penelitian ini dilakukan pengkajian penerapan metode interpolasi geostatistika dalam pengolahan data hasil survei geofisika udara. Data yang diolah adalah data magnetik. Metode geostatistika yang diterapkan adalah dua buah teknik Kriging, yakni Simple Kriging dan Disjuntive Kriging dengan aproksimasi Gaussian Kernels dan Density Skew.

Survei magnetik ini bertujuan untuk mendeteksi secara langsung deposit bijih logam melalui penggambaran anomali magnetik. Adapun tujuan lainnya adalah untuk menentukan tren, cakupan dan geometri dari badan magnetik di suatu daerah, serta untuk penafsiran geologi (Ford dkk., 2007). Kajian yang lain juga menunjukkan bahwa survei magnetik dapat dipakai untuk mengidentifikasi anomali magnetik guna memberikan gambaran menyeluruh terhadap komposisi dan pola struktur batuan (Lyatsky, 2010).

\section{METODOLOGI}

Data magnetik dapat digunakan untuk pemetaan geologi. Data ini pun digunakan untuk menginvestigasi dan mengestimasi kedalaman dan struktur sedimentary basin untuk mendapatkan informasi terkait eksplorasi hidrokarbon dan eksplorasi sumberdaya alam lainnya (Pitcher dkk., 1994). Data magnetik yang telah dikoreksi selanjutnya diolah untuk mendapatkan DTM dengan menggunakan metode interpolasi spasial. Metode interpolasi spasial yang akan digunakan merupakan metode hasil pengkajian dari metode-metode yang ada berdasarkan kemudahan penggunaan, efisiensi dalam komputasi, dan hasil yang akurat. Hal ini berdasarkan beberapa penelitian yang dilakukan oleh McKinley dkk. (2014). Metodologi yang diterapkan dalam penelitian ini dapat dilihat pada Gambar 1. Data magnetik yang telah dikoreksi selanjutnya diolah menggunakan metode Geostatistika Kriging dengan menggunakan teknik Simple Kriging dan Disjunctive Kriging. Aproksimasi yang diterapkan adalah Gaussian Kernels dan Density Skew. Hasil yang diperoleh selanjutnya akan 
memberikan Semivariogram dan Cross Validation. Berdasarkan hasil ini selanjutnya dilakukan pengujian data, apabila data memenuhi persyaratan dalam pengujian, maka selanjutnya hasil dari pengolahan kedua teknik ini dibandingkan.

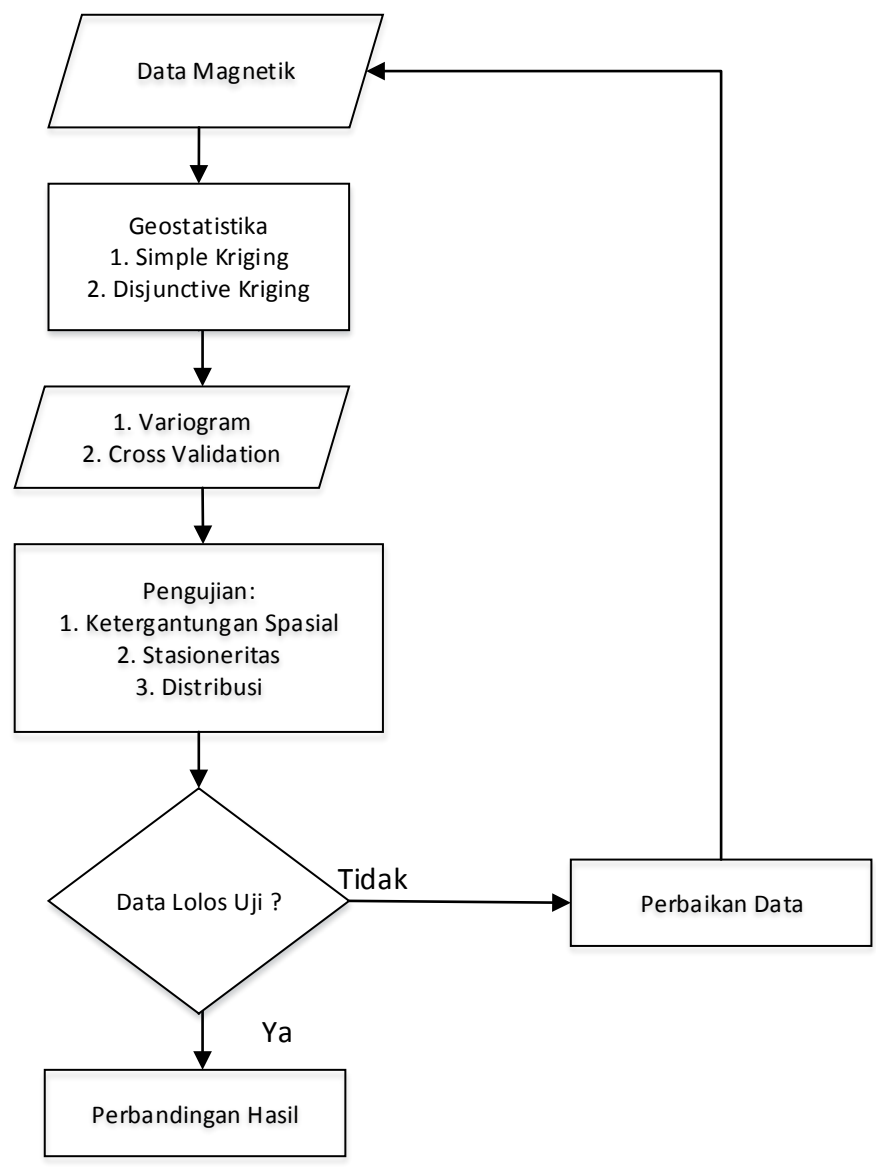

Gambar 1. Metodologi Penelitian

\subsection{Daerah Penelitian}

Daerah penelitian secara administratif berada di wilayah Komopa-Dawagu, dimana di dalamnya terdapat kawasan Ipowo. Sebagian besar wilayah penelitian termasuk dalam area Kabupaten Painai, Provinsi Papua. Wilayah penelitian meliputi area $50 \mathrm{~km} \times 20 \mathrm{~km}$ dengan ketinggian wilayah berkisar antara $1.720-2.200 \mathrm{mdpl}$. Daerah penelitian dibatasi di wilayah selatan oleh Sungai Aga dan Bogodide. Area Komopa dan Ipowo dipisahkan oleh Sungai Wodege di wilayah barat daya dan tenggara. Total luas permukaan area Komopa-Ipowo sekitar $22 \mathrm{~km}^{2}$. Wilayah ini adalah wilayah yang terbuka dengan sebagian area merupakan kawasan hutan tropis, persawahan, perladangan, dan pemukiman penduduk. Secara fisiografis area ini berada pada Zona Gunungapi Jayawijaya. Daerah ini ditandai oleh lembah yang cukup lebar yaitu antara $600 \mathrm{~m}$ sampai $1200 \mathrm{~m}$, yang meliputi bahan aluvial yang dipisahkan oleh perbukitan rendah (PT. Freeport Indonesia, 1996).

\subsection{Data}

Data yang digunakan dalam penelitian ini adalah data magnetik hasil survei geofisika udara yang bersumber dari PT. Freeport Indonesia dan dikerjakan pada tahun 1983-1984. 


\subsection{Pengujian Data}

Geostatistik adalah seperangkat model dan alat yang dikembangkan untuk analisis statistik data kontinyu. Data ini dapat bersumber dari mana pun, dapat diukur di lokasi mana pun, namun dengan jumlah titik sampel yang terbatas. Data yang diinputkan umumnya mengandung kesalahan dan model yang digunakan dalam perhitungan hanyalah perkiraan dari kenyataan, dengan demikian titik prediksi yang dihitung dalam analisis geostatistika akan mengandung ketidakpastian. Langkah yang dilakukan dalam analisis data statistik ini adalah melakukan verifikasi tiga fitur data, yaitu ketergantungan (dependency), stasioneritas, dan distribusi (Krivoruchko, 2017). Jika data bersifat independen, maka data tidak dapat dianalisis menggunakan metode geostatistik. Jika data tidak stasioner, maka data perlu dibuat menjadi stasioner. Hal ini dapat dilakukan dengan metode detrending data dan transformasi data. Begitu pula jika data tidak terdistribusi normal atau mengikuti distribusi Gauss maka data harus dibuat agar mendekati distribusi Gauss.

\subsubsection{Pengujian Ketergantungan Secara Spasial}

Derajat ketergantungan secara spasial antartitik atau antarsampel diukur dengan menggunakan besaran variance atau semivariance. Besar nilai (magnitude) dari semivariance antartitik tergantung pada jarak antartitik. Plot dari semivariance sebagai fungsi dari jarak antara satu titik dengan titik lainnya disebut sebagai semivariogram atau variogram. Variogram digunakan sebagai alat untuk memodelkan bagaimana dua nilai di dalam ruang atau waktu saling berkorelasi. Dengan demikian dapat diketahui bahwa dua nilai di dalam ruang (spasial) yang saling berdekatan akan cenderung saling serupa dibandingkan dengan dua nilai yang saling terpisah jauh (ketergantungan secara spasial) (Krivoruchko, 2017).

\subsubsection{Pengujian Stasioneritas}

Pendekatan statistik mensyaratkan agar observasi direplikasi untuk memperkirakan ketidakpastian prediksi. Stationarity berarti bahwa sifat statistik tidak bergantung pada lokasi yang tepat. Oleh karena itu, mean (expected value) suatu variabel di satu lokasi sama dengan mean di lokasi lain. Begitu pula varian data akan konstan di area yang diteliti dan korelasi (kovariansi atau semivariogram) antara dua lokasi hanya bergantung pada vektor yang memisahkannya, dan bukan pada lokasi sebenarnya. Untuk data stationarity, seluruh data memiliki kesamaan spasial yang hampir serupa (dependensi). Ini menjadikan replikasi statistik dalam media spasial dapat dimungkinkan sehingga prediksi nilai titik dapat dilakukan. Korelasi spasial adalah pemodelan yang merupakan fungsi dari jarak antarpasang lokasi. Fungsi seperti itu disebut kovariansi dan semivariogram. Kriging menggunakannya untuk membuat prediksi yang optimal (Krivoruchko, 2017).

\subsubsection{Pengujian Distribusi Data}

Poin pada plot Normal QQ (Quantile to Quantile) memberikan indikasi normalitas univariat dataset. Jika data terdistribusi normal, titik-titik tersebut akan jatuh pada garis referensi 45 derajat. Jika datanya tidak terdistribusi normal, titik-titiknya akan menyimpang dari garis referensi. Plot Normal QQ memberikan perbandingan visual dataset terdistribusi normal standar, dan hal ini dapat digunakan untuk melihat titik-titik yang menyebabkan penyimpangan dari distribusi normal dengan memilihnya diplot dan memeriksa lokasinya di peta (Krivoruchko, 2017).

\subsection{Membandingkan Metode Geostatistika}

Dalam membandingkan beberapa metode geostatistika untuk data magnetik ini perlu memperhatikan beberapa hal. Umumnya, model terbaik adalah yang memiliki mean standar terdekat dengan nol, root-mean-squared prediction error terkecil, standard error yang sangat 
dekat dengan root-mean-squared prediction error, dan standardized root-mean-squared prediction error mendekati satu (Johnston dkk., 2001).

Terdapat dua hal yang perlu dipertimbangkan saat membandingkan hasil perhitungan dari berbagai metode dan/atau model: satu adalah optimalitas dan kedua adalah validitas. Misalnya, kesalahan prediksi root-mean-squared prediction error mungkin lebih kecil untuk model tertentu, sehingga dapat disimpulkan bahwa model yang memenuhi kriteria itu adalah model yang optimal. Namun, bila dibandingkan dengan model lain, kesalahan root-meansquared prediction error mungkin mendekati perkiraan average estimated prediction standard error. Model ini lebih valid karena ketika dilakukan prediksi pada suatu titik tanpa data, maka hasilnya akan memiliki perkiraan kesalahan standar untuk menilai ketidakpastian prediksi ini. Dengan demikian harus dilakukan pemeriksaan terhadap standard root-meansquare, dimana nilainya harus mendekati satu.

\section{HASIL DAN PEMBAHASAN}

\subsection{Pengujian Data}

Dalam melakukan pengujian data, dilakukan pengujian untuk fitur ketergantungan (dependency), stasioneritas, dan distribusi data.

\subsubsection{Pengujian Ketergantungan}

Pengujian ketergantungan dilakukan dengan melakukan pengukuran derajat ketergantungan secara spasial antartitik atau antarsampel yang diukur dengan menggunakan besaran variance atau semivariance. Besaran ini diperoleh dari hasil perhitungan semivariogram. Semivariogram ini adalah gambaran distribusi titik yang diperlihatkan dalam bentuk grafik semivariogram. Jika titik-titik tersebut terkumpul secara dekat, maka dapat dipastikan bahwa data memiliki ketergantungan secara spasial. Pada Gambar 2 dan Gambar 3 dapat dilihat hasil pengolahan Semivariogram dan Cross Validation.

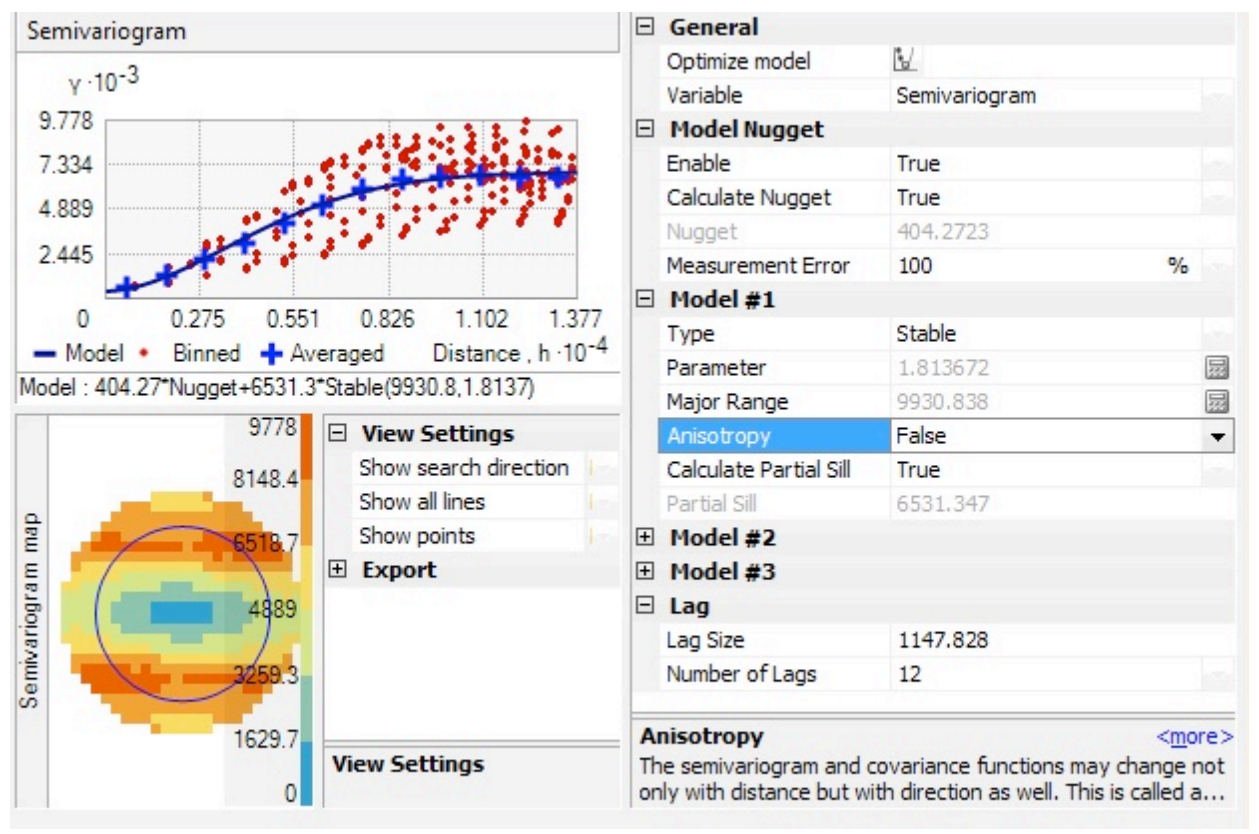

Gambar 2. Data Semivariogram 
Dapat dilihat dalam grafik semivarogram bahwa titik-titik dalam grafik berkumpul dan saling dekat antara satu dengan lainnya. Begitu pula dengan grafik cross validation pada Gambar 3 yang memperlihatkan bahwa titik-titik terkonsentrasi pada garis dengan kemiringan tertentu. Dengan demikian dapat disimpulkan bahwa data pengamatan magnetik yang digunakan dalam penelitian ini memiliki dependensi secara spasial.

\begin{tabular}{clll|l|l|l|l|}
\hline Source ID & Included & Measured & Predicted & Error & Standard Error & Standardized Error & Normal Value \\
-1 & Yes & $41182 \ldots$ & $41182 \ldots$ & $0 \ldots$ & $22.0362534 \ldots$ & $0.00722061334 \ldots$ & $0.394907 \ldots$ \\
-1 & Yes & $41182 \ldots$ & $41182 \ldots$ & $0 \ldots$ & $21.7243501 \ldots$ & $0.00585873919 \ldots$ & $0.338682 \ldots$ \\
-1 & Yes & $41182 \ldots$ & $41182 \ldots$ & $0 \ldots$ & $21.4987690 \ldots$ & $0.00454850586 \ldots$ & $0.281662 \ldots$ \\
-1 & Yes & $41182 \ldots$ & $41182 \ldots$ & $0 \ldots$ & $21.3284882 \ldots$ & $0.00288756925 \ldots$ & $0.206007 \ldots$ \\
-1 & Yes & $41182 \ldots$ & $41182 \ldots$ & $0 \ldots$ & $21.1954948 \ldots$ & $0.00125627172 \ldots$ & $0.121980 \ldots$ \\
-1 & Yes & $41182 \ldots$ & $41182 \ldots$ & $0 \ldots$ & $21.0891067 \ldots$ & $0.00029611193 \ldots$ & $0.053815 \ldots$ \\
-1 & Yes & $41182 \ldots$ & $41182 \ldots$ & $0 \ldots$ & $21.0891044 \ldots$ & $0.00020276729 \ldots$ & $0.044623 \ldots$ \\
-1 & Yes & $41182 \ldots$ & $41182 \ldots$ & $0 \ldots$ & $21.0891052 \ldots$ & $0.00035183460 \ldots$ & $0.058857 \ldots$ \\
-1 & Yes & $41182 \ldots$ & $41182 \ldots$ & $0 \ldots$ & $21.0890900 \ldots$ & $0.00037012534 \ldots$ & $0.060410 \ldots$ \\
-1 & Yes & $41182 \ldots$ & $41182 \ldots$ & $0 \ldots$ & $21.0890770 \ldots$ & $0.00067113484 \ldots$ & $0.084817 \ldots$ \\
-1 & Yes & $41182 \ldots$ & $41182 \ldots$ & $0 \ldots$ & $21.0891031 \ldots$ & $0.00062974964 \ldots$ & $0.081617 \ldots$ \\
-1 & Yes & $41182 \ldots$ & $41182 \ldots$ & $0 \ldots$ & $21.0890550 \ldots$ & $0.00029569173 \ldots$ & $0.053707 \ldots$ \\
-1 & Yes & $41182 \ldots$ & $41182 \ldots$ & $0 \ldots$ & $21.0890502 \ldots$ & $0.00066536024 \ldots$ & $0.084267 \ldots$ \\
-1 & Yes & $41182 \ldots$ & $41182 \ldots$ & $0 \ldots$ & $21.0890503 \ldots$ & $0.00077629927 \ldots$ & $0.092009 \ldots$ \\
-1 & Yes & $41182 \ldots$ & $41182 \ldots$ & $0 \ldots$ & $21.0890547 \ldots$ & $0.00061016830 \ldots$ & $0.080157 \ldots$ \\
-1 & Yes & 41183 & $41183 \ldots$ & $0 \ldots$ & $21.0890647 \ldots$ & $0.00057292612 \ldots$ & $0.077409 \ldots$ \\
-1 & Yes & $41183 \ldots$ & $41183 \ldots$ & $0 \ldots$ & $21.0890789 \ldots$ & $0.000887739752 \ldots$ & $0.099449 \ldots$ \\
-1 & Yes & $41183 \ldots$ & $41183 \ldots$ & $0 \ldots$ & $21.0890915 \ldots$ & $0.00090809125 \ldots$ & $0.100925 \ldots$ \\
-1 & Yes & $41183 \ldots$ & $41183 \ldots$ & $0 \ldots$ & $21.0891004 \ldots$ & $0.00068217348 \ldots$ & $0.085462 \ldots$ \\
-1 & Yes & $41183 \ldots$ & $41183 \ldots$ & $0 \ldots$ & $21.0891087 \ldots$ & $0.00064712138 \ldots$ & $0.082879 \ldots$ \\
-1 & Yes & $41183 \ldots$ & $41183 \ldots$ & $0 \ldots$ & $21.0891145 \ldots$ & $0.00094553246 \ldots$ & $0.103412 \ldots$ \\
-1 & Yes & $41183 \ldots$ & $41183 \ldots$ & $0 \ldots$ & $21.0891168 \ldots$ & $0.00075817098 \ldots$ & $0.090723 \ldots$ \\
\hline & $\ldots$ & $\ldots \ldots$ & $\ldots \ldots$ & $\ldots$ & $\ldots$ & $\ldots$
\end{tabular}

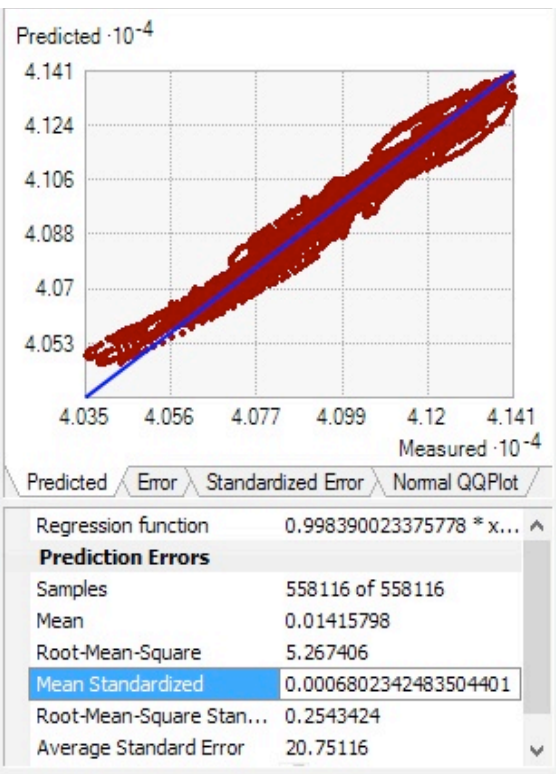

Gambar 3. Data Cross Validation

\subsubsection{Pengujian Stasioneritas}

Dalam pengujian stasioneritas suatu data dapat digunakan grafik semivariogram. Petunjuk yang dapat digunakan adalah apabila grafik semivariogram berbentuk omnidirectional, maka hal ini dapat dipakai sebagai indikasi nonstationarity karena semivariogram meningkat secara eksponensial dan tidak mendekati asimtot yang mewakili varians data (Krivoruchko, 2017). Dengan demikian apabila dilihat dari grafik semivariogram dalam Gambar 2, maka dapat disimpulkan bahwa data merupakan data yang stasioner.

\subsubsection{Pengujian Distribusi Data}

Gambar 4 adalah gambar plot normal QQ. Grafik ini menunjukkan bahwa kumpulan data ini merupakan data yang terdistribusi secara Gaussian atau terdistribusi normal. Hal ini dikarenakan titik-titik data jatuh pada garis referensi 45 derajat (Johnston dkk., 2001).

Dengan terpenuhinya ketiga persyaratan awal sebelum dilakukannya perhitungan, maka dapat disimpulkan bahwa data yang dijadikan data penelitian telah memenuhi tiga persyaratan yang dibangun dalam persamaan matematika untuk melanjutkan perhitungan geostatistika kriging. 

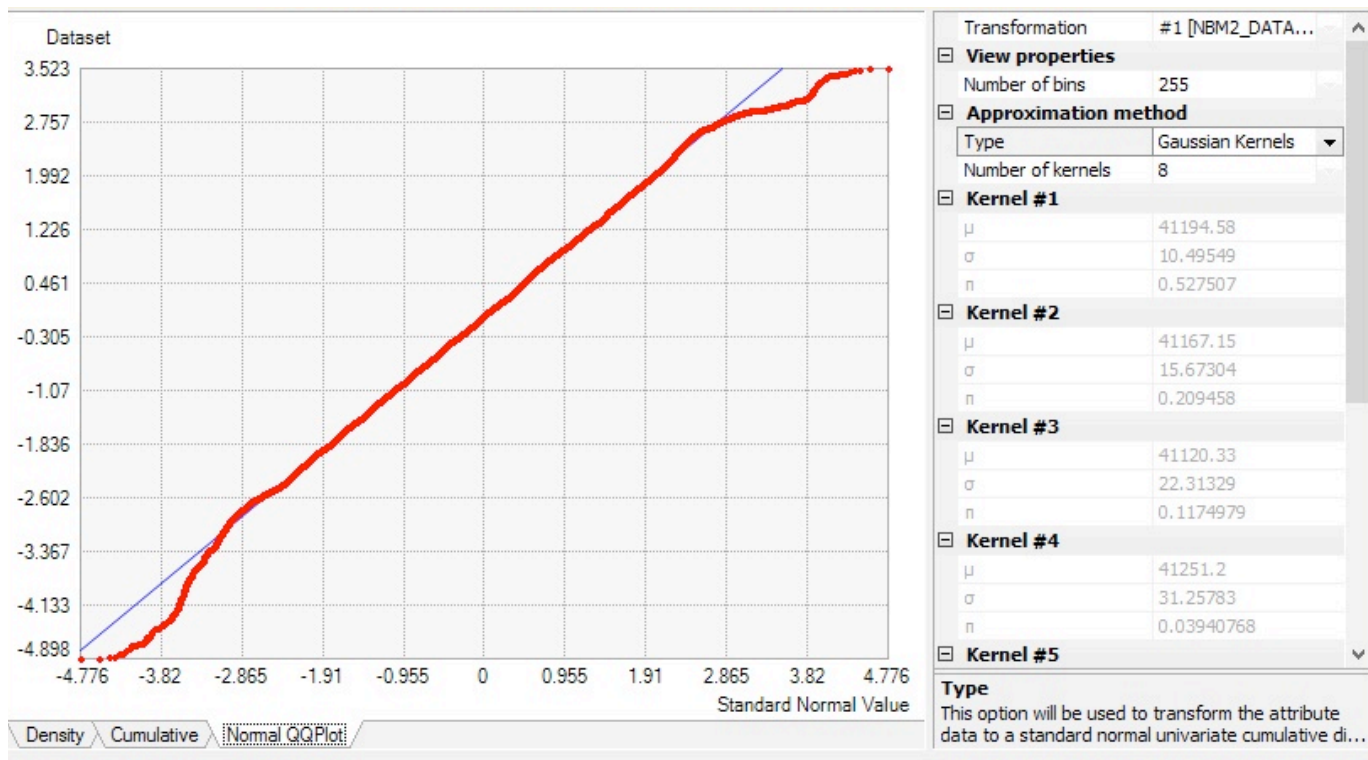

Gambar 4. Plot Normal QQ

\subsection{Hasil Pengolahan Data}

Hasil yang didapatkan dari pengolahan data magnetik menggunakan metode Simple Kriging dan Disjunctive Kriging dapat dilihat pada Tabel 1.

Tabel 1. Hasil Pengolahan Geostatistika

\begin{tabular}{|c|c|c|c|c|c|c|}
\hline \multirow{2}{*}{$\begin{array}{c}\text { Method Type } \\
\text { Variogram }\end{array}$} & \multicolumn{4}{|c|}{ Simple } & \multicolumn{2}{|c|}{ Disjunctive } \\
\hline & Semivariogram & Covariance & Semivariogram & Covariance & Semivariogram & Covariance \\
\hline Output type & Prediction & Prediction & Prediction & Prediction & Prediction & Prediction \\
\hline Approximation & $\begin{array}{c}\text { Gaussian } \\
\text { Kernels }\end{array}$ & $\begin{array}{l}\text { Gaussian } \\
\text { Kernels }\end{array}$ & Density Skew & Density Skew & Density Skew & Density Skew \\
\hline - Samples & 558116 & 558116 & 558116 & 558116 & 558116 & 558116 \\
\hline - Mean & $-0,7026151$ & $-0,9980846$ & $-0,6842026$ & $-0,545082$ & 0,1027108 & $-0,083768$ \\
\hline - RMS & 6,185646 & 8,102046 & 7,392544 & 7,491666 & 6,031196 & 5,055447 \\
\hline - Mean Standard & $-0,05287393$ & $-0,06110739$ & $-0,02464871$ & $-0,02297999$ & 0,01032315 & $-0,01206789$ \\
\hline - RMS Standard & 0,4247927 & 0,4341056 & 0,3577511 & 0,4367088 & 0,6076489 & 0,6867014 \\
\hline $\begin{array}{l}\text { - RMS Average } \\
\text { Standard Error }\end{array}$ & 20,7327 & 25,72254 & 26,11796 & 23,59631 & 9,833167 & 7,28141 \\
\hline $\begin{array}{l}\text { - Number of } \\
\text { Lags }\end{array}$ & 12 & 12 & 12 & 12 & 12 & 12 \\
\hline - Lag size & $1.679,41$ & $1.679,41$ & $1.590,55$ & $1.590,55$ & $1.590,55$ & $1.590,55$ \\
\hline - Nugget & 0,0453207 & 0,07106271 & 0,04776118 & 0,04184057 & 0 & 0 \\
\hline - Model Type & Stable & Stable & Stable & Stable & Spherical & Spherical \\
\hline - Parameter & 1,61679 & 2 & 1,773242188 & 2 & & \\
\hline - Range & $14.069,44$ & $10.108,80$ & $12.495,16$ & $9.718,48$ & $15.277,67$ & $11.797,63$ \\
\hline - Anisotropy & No & No & No & No & No & No \\
\hline - Partial Sill & 1,1356361 & 0,9315453 & 1,148505 & 0,965500085 & 1,192974022 & 1,0652191 \\
\hline
\end{tabular}


Dalam tabel dapat terlihat bahwa nilai mean standard terkecil diperoleh oleh Disjunctive Kriging, begitu pula dengan nilai root mean square average standard error (RMS average standard error) terkecil dicapai oleh Disjunctive Kriging dan nilai root mean square standard (RMS Standard) diperoleh oleh Disjunctive Kriging karena paling mendekati nilai satu (Johnston dkk. 2001).

DTM data magnetik hasil pengolahan data metode geostatistika dengan teknik Disjunctive Kriging dapat dilihat pada Gambar 5.

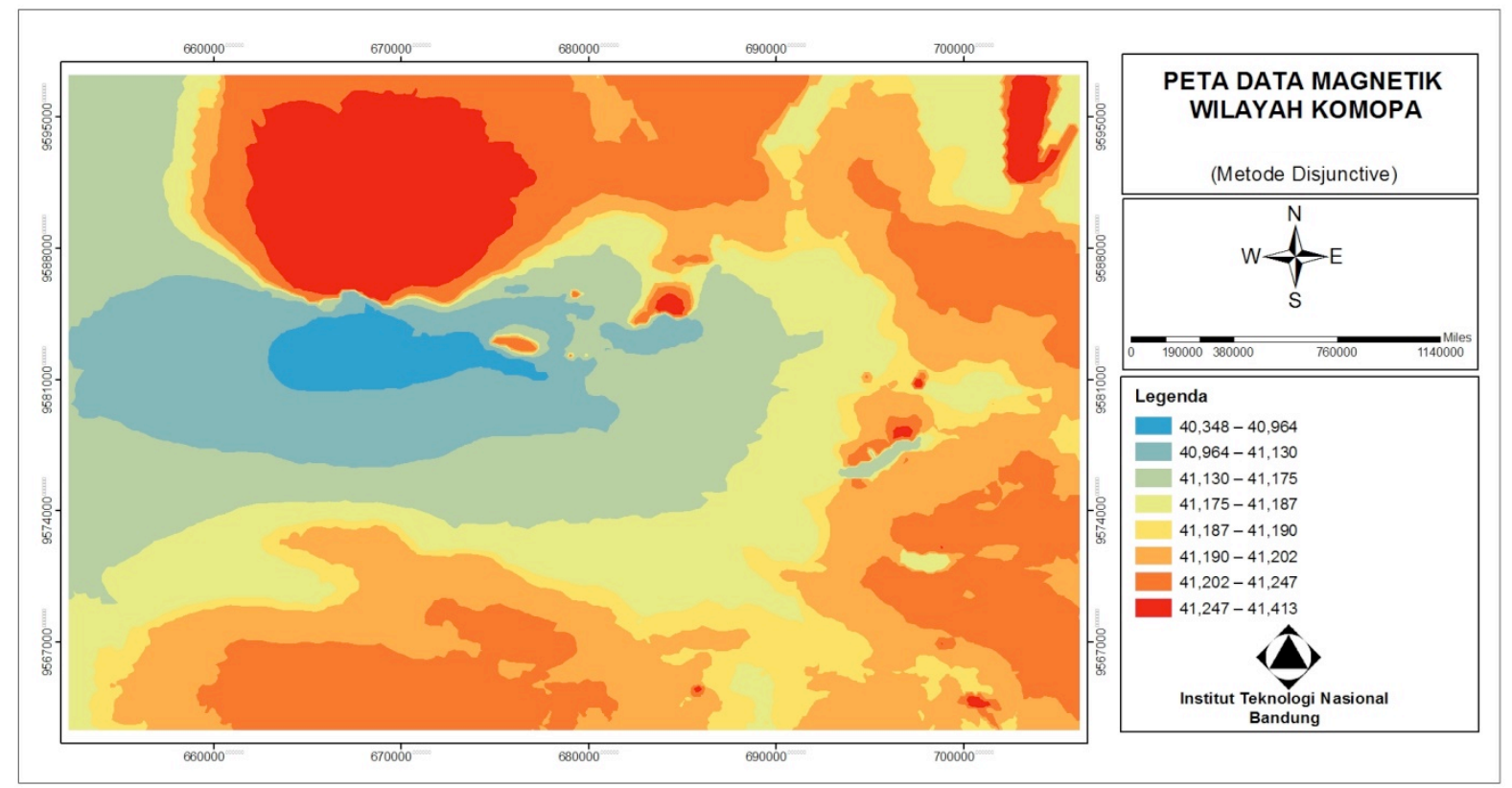

Gambar 5. DTM Data Magnetik dengan Metode Geostatistika Disjunctive Kriging

\section{KESIMPULAN}

Berdasarkan hasil analisis, maka dapat disimpulkan bahwa data yang digunakan dalam penelitian ini telah memenuhi kriteria sebagai data yang memiliki ketergantungan secara spasial, memenuhi kriteria stasioneritas, dan data terdistribusi secara normal. Selanjutnya data magnetik ini telah dihitung menggunakan metode Geostatistika Kriging dengan teknik Simple Kriging dan Disjunctive Kriging, masing-masing dengan aproksimasi Gaussian Kernel dan Density Skew. Hasil perhitungan menunjukkan bahwa metode geostatistika dengan teknik Disjunctive Kriging dengan aproksimasi Density Skew memberikan hasil yang lebih baik daripada teknik Simple Kriging dengan aproksimasi Gaussian Kernels maupun Density Skew.

\section{UCAPAN TERIMA KASIH}

Penulis mengucapkan terima kasih kepada PT. Freeport Indonesia, PT. Eksplorasi Nusa Jaya, dan Bapak Aditya Widjojo Pringgoprawiro yang telah mengizinkan untuk menggunakan data geofisika udara pada wilayah Komopa, Provinsi Papua. 


\section{DAFTAR RUJUKAN}

Cornwell, J. D., Kimbell, S. F., Evans, A. D., dan Cooper, D. C. (1995). A review of detailed airborne geophysical surveys in Great Britain, Mineral Reconaissance Programme Report. British Geological Survey, (136).

Ford, K., Keating, P. dan Thomas, M.D. (2007). Overview of Geophysical Signatures Associated With Canadian Ore Deposits in Mineral deposits of Canada: a Synthesis of Major Deposit-types, District Metallogeny, The Evolution of Geological Provinces, and Exploration Methods; by Goodfellow, W D (ed.); Geological Association of Canada, Mineral Deposits Division, Special Publication no. 5, 2007 p. 939-970.

Guastaldi, E., Baldoncini, M., Bezzon, G., Broggini, C., Buso, G., Caciolli, A. dan Fiorentini, G. (2013). A Multivariate Spatial Interpolation of Airborne -ray Data Using The Geological Constraints. Remote Sensing of Environment, 137, 1-11.

IAEA (International Atomic Energy Agency). (2013). Nuclear Energy Series, Advances in Airborne and Ground Geophysical Methods for Uranium Exploration, No. NF-T-1.5.

Johnston, K., Ver Hoef, J. M., Krivoruchko, K. dan Lucas, N. (2001). Using ArcGIS Geostatistical Analyst. GIS by ESRI.

Krivoruchko, K. (2017). Introduction to Modelling Spatial Processes Using Geostatistical Analysist. ESRI Press. Dipetik 26 Agustus 2017 dari: www.esri.com/library/whitepapers/pdfs/intro-modeling.pdf.

Lyatsky, H. (2010). Magnetic and Gravity Methods in Mineral Exploration: the Value of WellRounded Geophysical Skills, CSEG (Canadian Society of Exploration Geophysicists). RECORDER | Oct 2010 | Vol. 35 No. 08.

McKinley, J. M., Deutscht, C. V., Neufeldt, C., Patton, M., Cooper, M., dan Young, M. E. (2014). Use of Geostatistical Bayesian Updating to Integrate Airborne Radiometrics and Soil Geochemistry to Improve Mapping for Mineral Exploration. Journal of the Southern African Institute of Mining and Metallurgy, 114(8), 575-575.

Pitcher, D.H., Steele, J.P., dan Watson, R.K. (1994). The Application of Airborne Geophysical Techniques to The Delineation of Hydrothermal Systems in Base and Precious Metal Deposit. Northwest Mining Association Conference.

PT. Freeport Indonesia (1996). Contract of Work (COW) Exploration, 1994-1996 Fieldwork in Komopa-Dawagu area General Sysnthesis. Technical Report, April 1996 EX08, Author: M.B. Skead.

Scott, W., J. (2014). Geophysics for Mineral Exploration, A Manual for Prospectors. Prepared for Matty Mitchell Room, Newfoundland and Labrador Department of Natura, Resources.

Yanbing, W., Lixin, W., Wenzhong, S., dan Xiaomeng, L. (2007). On 3D GIS spatial modeling. In ISPRS Workshop on Updating Geospatial Databases with Imagery \& The 5th ISPRS Workshop on DMGISs. ISPRS. 